\title{
Magnitude of the Mueller-Lyer illusion in children as a function of pigmentation of the Fundus oculi'
}

ROBERT H. POLLACK AND S. D. SLLYAR

INSTITUTE FOR JUVENILE RESEARCH, CHICAGO

Fifteen Ss (13 Negroes, two whites) rated as having dense or dark pigmentation at the Fundus oculi were compared with 20 Ss (one Negro, 19 whites) rated as lightly pigmented with respect to their sensitivity to a part of the Mueller-Lyer figure. The darkly pigmented $S$ s were significantly less sensitive than the lightly pigmented Ss. Biserial correlation of magnitude of illusion with pigmentation rating yielded a coefficient of -.745 .

In a recent study (Silvar \& Pollack, 1967), it was found that 13 of 14 Negro children were rated as having dense or dark pigmentation of the Fundus oculi ${ }^{2}$ while 24 of 26 white children were rated has having light pigmentation. These results are similar to those of Ishak (1952a, b) who found that Egyptians exhibited markedly deeper macular pigmentation than Europeans and that this increased density was associated with higher luminosity thresholds in the shortwave region of the visible spectrum. Further support for the notion that deeper retinal pigmentation renders the eye less sensitive is lent by Weale's (1961) report of increasing density of macular pigmentation with age accompanied by loss of efficiency of various visual functions. In the field of perception, it has been demonstrated (Segall, Campbell, \& Herskovits, $1963,1966)$ that members of non-European societies, who possess in general deeper skin pigmentation than their European counterparts, were less sensitive to two primary (Mueller-Lyer and Sander parallelogram) geometric illusions whose magnitudes could well depend on the density of retinal pigmentation (Pollack, 1966). It is interesting to note that the ontogenetic trends in the non-European groups were identical to those found for European groups (Wohlwill, 1960; Pollack, 1963).

This investigation was undertaken to see whether or not rated differences in pigmentation of the Fundus oculi might be related to the magnitude of the MuellerLyer illusion. Earlier work with this illusion indicated a negative correlation between sensitivity to contour (Pollack, 1963) and magnitude of illusion. Taking Ishak's results into account, it was felt that exposure of a Mueller-Lyer figure in blue ilumination would maximize differences between light and dark pigmented Ss by reducing the intensity of the illusion figure's contours in deeply pigmented Ss.

\section{Subjects 3}

Ss were 35 of the 40 male children between the ages of 8 and 12 previously studied by Silvar \& Pollack (1967). All 14 of the Negro boys and 21 of the 26 whites were retained. The two whites who exhibited dark optical pigmentation, as well as the one Negro with light pigmentation, were included. The two pigment groups were equated as closely as possible for age, school grade, and reading achievement level. All Ss were puplls in the integrated school system of a middle class suburb with a rather narrow income range.

\section{Apparatus}

Nineteen stimuli were constructed for tachistoscopic use. Each stimulus consisted of the open component (forked ends connected by a straight line) of the Mueller-Lyer figure, and a comparison line opposite it drawn in white ink on a black $5 \times 7$ in. card. In each case the top of the comparison line was $5 \mathrm{~mm}$ lower than the top of the standard line. Each forked line was drawn in a vertical orientation and was placed $1 \mathrm{~cm}$ to the left of a centered fixation dot $1 \mathrm{~mm}$ in diameter. The angle between the lines of the forks was $90 \%$, the length of the forked lines was $5 \mathrm{~mm}$, and the vertical line connecting the two forks was $22 \mathrm{~mm}$ long. The straight vertical comparison line was placed $1 \mathrm{~cm}$ from the center dot on the right side of the card. These lines varied in length from 20 to $29 \mathrm{~mm}$ in $1 / 2-\mathrm{mm}$ steps. The maximum dimensions of the stimulus figures were $1^{\circ} 30^{\prime}$ vertical by $1^{\circ} 15^{\prime}$ horizontal.

The tachistoscope was a three-channel electronic tachistoscope (Model G) made by Scientific Prototype Manufacturing Corp. The intensities of all three channels were kept at a constant $1.91 \mathrm{ft}$.-c. in each channel, as measured by a Macbeth Illuminometer at the eyepiece.

The stimull were presented with no color correction for the characteristics of the gas discharge lamps. An analysis by the Scientific Prototype Corporation of the spectral energy distribution of the lamps yielded a peak of $325 \mu \mathrm{W} / 10$ nan/lumen at about 440 nan. Channel 2 was used for the figures because its half mirror lent an even bluer cast to its appearance. Procedure

In the simultaneous presentation condition $S$ was shown a card, front-lit in Channel 2 of the tachistoscope, on which the comparison line was obviously 
longer than the Mueller-Lyer line and another one on which the line was obviously ahorter. He was told that in following presentations the comparison line would sometimes be longer than the line between the forks and sometimes shorter; he was to say "longer" when it looked longer and "shorter" when it looked shorter; he was never to say "same length." Eight convergent method of limits series of 19 trials each were then run, the comparison line in each series being (all values in $\mathrm{mm}$ ): $20,29,28.5,20.5,21,28$, $27.5,21.5,22,27,26.5,22.5,23,26,25.5,23.5,24$, 25, 24.5. Exposure time of each presentation was $500 \mathrm{msec}$.

\section{Results and Discussion}

The results were clearcut. The more deeply pigmented Ss produced smaller illusion magnitudes $(M=$ $2.83 \mathrm{~mm}$ ) than the lightly pigmented Ss $(M=3.89 \mathrm{~mm})$. The difference was significant $(t=3.89$, df $=33, p<$ .01). Biserial correlation of optical pigmentation with illusion score yielded a coefficient of -.745 . The single Negro judged as lightly pigmented indicated an illusion magnitude of $3.55 \mathrm{~mm}$, somewhat smaller than the light-pigment mean but greater than that for six of the white boys with light pigmentation. The two whites judged as being deeply pigmented showed magnitudes of $3.15 \mathrm{~mm}$ and $2.55 \mathrm{~mm}$. Four of the Negro boys with dark pigmentation had magnitudes larger than $3.15 \mathrm{~mm}$ and nine had magnitudes larger than $2.55 \mathrm{~mm}$. Thus, optical pigmentation rather than race membership appears to be the more important variable affecting sensitivity to the illusion. Certainly, additional research and more detailed research is called for, but at present, density of pigmentation of the Fundus ocull appears to affect visual sensitivity to those stimulus characteristics determining magnitude of a primary optico-geometrical illusion.

\section{Roferences}

Ishak, I. G. H. The photopic luminosity curve for a group of fifteen Egyptian trichromats. J. Opt. Soc. Amer., 1952a, 42, 529-534. Ishak, I. G. H. The spectral chromaticity coordinates for one British and eight Egyptian trichromats. J. Opt. Soc. Amer., 1952b, 42, 534-539.

Pollack, R. H. Contour detectability thresholds as a function of chronological age. Percept. mot. Skills, 1963, 17, 411-417.

Pollack, R. H. Non-developmental age changes in the perception of children. In N. S. Jenkin \& R. H. Pollack (Eds.), Perceptual development: Its relation to theories of intelligence \& cognition. Proceedings of a conference sponsored by Institute for Juvenile Research and National Institute of Child Health and Human Development. Chicago, 1966. Pp. 82-102.

Segall, M. H., Campbell, D. T., \& Herskovits, M. J. Cultural differences in the perception of geometric illusions. Science, 1963 , $139,769-771$.

Segall, M. H., Campbell, D. T., \& Herskovits, M. J. The influence of culture on visual perception. Indianapolis, Indiana: The Bobbs-Merrill Company, 1966.

Silvar, S. D., \& Pollack, R. H. Racial differences in pigmentation of the Fundus oculi. Psychon. Sci., 1967, 7, 159-160.

Wohlwill, J. F. Developmental studies of perception. Psychol. Bull., 1960, 57, 249-288.

\section{Notes}

1. This research was supported by Grant No. HD 01433 awarded by the National Institute of Child Health and Human Development. 2. This includes the pigmentation of the choroidal and retinal pigmentation layers and the yellow pigmentation of the Macula lutea. 3. I am grateful for the cooperation of Mr. Ivan A. Baker, Superintendent of Schools, and the principals of the Algonquin, Beacon Hill, Blackhawk Elementary and Junior High, Mohawk, Westwood Junior High, and Wildwood Schools in Park Forest, Illinois. 